\title{
The Ideal Multilingual Self: Validity, Influences on Motivation, and Role in a Multilingual Education
}

[This is the pre-publication copy of Henry, A. \& Thorsen, C. 'The Ideal Multilingual Self: Validity, Influences on Motivation, and Role in a Multilingual Education. To appear in the International Journal of Multilingualism]

\begin{abstract}
L2 motivation research has a longstanding monolingual bias. Recently, however, the motivational systems of a multilingual's different languages have been conceptualized as constituting a multilingual motivational system, and it has been suggested that interactions between the ideal Lx self and the ideal Ly self can lead to the emergence of an ideal multilingual self. While the notion of an ideal multilingual self chimes with research on multilinguals’ identity experiences, it has not been investigated empirically. The purpose of this study is to establish whether there is empirical support for the proposed ideal multilingual self construct, and whether it influences motivation to learn a second foreign language. A questionnaire containing items measuring the ideal L2 self and the ideal multilingual self was administered to a sample of secondary students $(N=324)$ at two schools in Sweden with international profiles. Using structural equation modeling, analyses yielded discriminant validity for the ideal multilingual self construct, and revealed an indirect influence on intended effort mediated via the ideal L2 self. On the strength of these results, a case is made for future research into people’s motivation to be or become multilingual, and educational interventions focused on developing students’ ideal multilingual selves.
\end{abstract}




\section{Introduction}

L2 motivation research has a longstanding monolingual bias. Although in Gardner’s (1985) model of L2 motivation the integrative motive contains a component measuring a general 'interest in foreign languages', and Dörnyei has argued that the ideal L2 self - the centerpiece of his L2 Motivational Self System model - is bolstered when learners have a 'broader cosmopolitan disposition’ (Dörnyei \& Al-Hoorie, 2017, p. 460), both models have an underlying monolingual logic (Henry, 2017). Empirically, motivation research has had a disproportionate focus on English, much work carried out in Asian settings, such as China and Japan, that are characterized by study authors as monolingual (Boo, Dörnyei \& Ryan, 2015; Ushioda, 2017). While motivation researchers can justifiably be criticized for adopting ‘a "no difference” assumption’ (De Angelis, 2007, p. 5), recent years have seen some shift in this position, and articles and book chapters examining motivation to learn languages other than English (LOTE) in multilingual settings are beginning to appear. Importantly, a number of these studies move beyond comparisons between the motivational dispositions for different languages, and investigate the effects on motivation of interactions between the languages in the learner's repertoire (e.g. Henry, 2011, 2014, 2016). In a special issue of The Modern Language Journal edited by Ushioda and Dörnyei (2017), a number of articles with a focus on motivation to learn LOTEs have been collected together, an important overarching question being whether established theoretical perspectives can adequately account for motivation to learn other foreign languages. Although much work remains before a categorical answer can be provided, it is clear from a number of contributions that not only does the conceptual base of Dörnyei’s (2005) model offer opportunities to understand motivation to learn LOTEs - for example in developing insights into what happens when the ideal L2 selves of different languages compete - but 
because L2 motivation is conceptualized as a self system, how the motivational systems of different languages are inter-related and how interactions lead to system-level motivational phenomena. Importantly, this systemic framing enables motivation research to engage with the complex motivational processes characteristic of contexts of multilingualism, and to investigate system-level influences on motivation to learn particular languages, for example the influence that an emerging multilingual identity can have on Lx and Ly motivation. Among a number of contributions exploring the ways in which multilingualism/plurilingualism can constitute a source of motivation (Busse, 2017; Dörnyei \& Al-Hoorie, 2017; Lasagabaster, 2017; Ushioda, 2017), Henry (2017) offers an account of how motivation to be/become multilingual ${ }^{i}$ can be conceptualized from a self-system perspective, arguing that in a situation where two or more additional languages are learnt or acquired simultaneously, people can develop an ideal multilingual self, and that this influences Lx and Ly motivation. While this argument draws on influential research on the identity experiences of multilinguals (e.g. Kramsch \& Huffmaster, 2015; Pavlenko, 2006), the proposals have not been empirically tested. Accordingly, the purpose of this study is to consider the validity of the ideal multilingual self construct, and in a Swedish setting, to explore possible influences on motivation to learn LOTEs.

\section{The ideal multilingual self}

An increasingly common feature of social life in many globalized societies, multilingualism is now the recognized starting point for models of language acquisition (Douglas Fir Group, 2016). By abandoning monolingualism as an organizing principle for language acquisition research, and triggering the development of alternatives to the 'predominant monolingual theories, constructs, and research practices' of SLA (Ortega, 2014, p. 33), the multilingual turn has brought about an epistemic reorientation (Douglas Fir Group, 2016; May, 2014; Ortega, 2014). Recognizing that 
the investigation of language learning processes and experiences requires consideration of all of the languages the individual knows and has experience of, research agendas are shifting from the study of languages to the investigation of language repertoires, and from conceptualizations of linguistic competence to conceptualizations of linguistic multi-competence (Cook, 2016). Importantly, the multilingual turn is not only informing linguistic theory and research practice; it is also bringing about a shift in the assumptions and aims of language learning pedagogy (Cenoz \& Gorter, 2011, 2015).

Until recently, the impact of the multilingual turn on conceptualizations of language learning motivation has been limited (Ushioda, 2017), with only a few studies examining motivation to learn different languages and the effects that motivation to learn one language can have on motivation to learn another. As in other fields in SLA where a monolingual mindset 'has been blocking a holistic view of multilingualism' (Jessner, 2006, p. 141), L2 motivation research has treated the motivational systems of different languages as separate entities, rather than as the interconnected constituents of larger identity systems. In an attempt to bring a holistic focus to L2 motivation research, Henry (2017) has argued that the motivational systems of the different languages a person is learning need to be understood as forming a larger multilingual motivational system, and that interactions between the self-guides of the different L2 motivational systems (i.e. the ideal Lx self, and the ideal Ly self) can lead to the emergence of multilingual self-guides ${ }^{\mathrm{ii}}$. One of these is the ideal multilingual self.

Like Dewaele (2011), Henry (2017) points to the powerful identity experiences connected to speaking several languages and, for many multilinguals, how the development of a multilingual identity that transcends and is unconstrained by a dominant language or languages can be a deeply enriching experience. In particular, he draws attention to studies by Pavlenko (2006) and 
Kramsch and Huffmaster (2015) which have explored the phenomenology of being/becoming multilingual. In Pavlenko’s (2006) study, people testified to a uniquely enjoyable and empowering experience of being multilingual, and described experiencing themselves as fortunate and bestowed with choices and options they would not otherwise have had. Thriving on the diversity created by moving between languages, and the 'hybridity and relativity of their existence', these multilinguals described a sense of feeling 'linguistically integrated' (p. 29). Importantly, Pavlenko makes the point that multilinguals with positive identity experiences may not perceive particular differences between their linguistic selves. ${ }^{\mathrm{iii}}$ In their study, Kramsch and Huffmaster (2015) argue that because being multilingual involves selecting between languages, multilinguals can find themselves living at the intersection between languages, and that multilinguals who experience a close affinity to their different languages can be understood as possessing a 'multilingual self' (p. 133).

Drawing on these insights, and the proposal by Aronin (2016) that a multilingual identity is holistic and encompasses all dimensions of the multilingual experience, including 'perceptions, attitudes and personal life scenarios, both real and possible’ (2016, p. 145), Henry (2017) argues that people who develop skills in more than one L2 can develop multilingual self-guides. In theories of self-discrepancy (Higgins, 1987), self-guides are 'self-directive standards or acquired guides for being' (p. 321) and strongly influence behavioral orientations. Self-discrepancy theory provides the epistemic foundation for Dörnyei’s theory of L2 motivation, his L2 Motivational Self System model containing two self-guides: the ideal L2 self and the ought-to L2 self. While the ideal L2 self is a desirable self-image of the kind of language-speaker/user the person would like to become, the ought-to L2 self reflects the attributes that the person believes he/she needs to possess in order to conform to the expectations of others and to avoid possible negative L2 
learning outcomes, and is thus less internalized than the ideal L2 self (Dörnyei, 2005, 2009). For both self-guides, motivation is generated by the recognition of a discrepancy between the actual state and the desired (or 'ideal') state, the discomfort associated with this gap causing the individual to take actions to reduce it.

As Henry $(2011,2017)$ has suggested, in situations of multiple learning/acquisition, the selfguides of the different language systems come into contact and interact, for example in conjunction with processes of crosslinguistic influence. Over time, and as a consequence of multiple interactions, processes of emergence lead to the development of multilingual selfguides. When interactions are complementary, an ideal multilingual self can develop. When this occurs, two things are theorized to happen. Not only will it operate together with the ideal Lx self and the ideal Ly self in generating motivation, but it can also function to create system-level cohesion and stability. This means that learning behaviors associated with each of the languages learned are likely to be become more closely related, development driven not only by the desire to achieve an ideal state as a speaker/user of the Lx and the Ly, but also an ideal state as a developing multilingual.

\section{Support for the ideal multilingual self}

So far, these proposals have not been empirically tested. However, there are indications that some learners may develop identities that reflect a deeper personal value attached to being/becoming multilingual. In addition to the previously discussed research on multilinguals' identity experiences (Kramsch \& Huffmaster, 2015; Pavlenko, 2006), Henry (2017) reports on how secondary students learning two or more LOTEs emphasize the sensory and perceptual aspects of being/becoming multilingual. Reflecting on whether they identified themselves as multilingual and, if so, the mental imagery associated with such identities, students described 
images indexing openness, empathy and discovery. For example, one student described her sense of being/becoming multilingual as possessing opportunities: 'Being able to speak several languages opens more doors. You are less limited. And so when I see myself in the future, I have an image that I am multilingual and I have opened more doors.' Interestingly, while some of the students had strong affiliations to the languages they were learning, for others the acquisition of a multilingual repertoire was as equally important as developing skills in constituent languages: ' $I$ don't think that it really makes such a great difference which languages I can speak. Sure, I want to speak them well. But I want to speak several languages'.

In addition to Henry's work, support for the idea that an aspiration to become multilingual and the development of a multilingual identity can influence motivation to learn a LOTE is to be found in research by Busse (2013, 2017). Reporting on the motivation of university students of German in England, Busse found that, for some of her participants, the ideal L2 self was not specifically associated with being a speaker/user of German, but rather 'the wish to become a plurilingual person in the future' (2017, p. 567). For students with this outlook, Busse suggests, motivation to learn German can be understood in the sense that aspired-to proficiency is not so much a question of wanting to develop communicative skills that facilitate personally rewarding interactions with TL speakers, but is rather part of a process of developing a cosmopolitan identity and as becoming ‘an educated European citizen’ (p. 568).

Referring to a study involving students studying for a degree in French and Spanish (Oakes, 2013), Busse $(2017,2015)$ points to similar motivational profiles, leading her to suggest that for some students learning a foreign language involves developing an identity that sets them apart from those who only speak their L1, and that this identity is as part of what she terms a 'plurilingual ideal Bildungs-Selbst' (Busse, 2015, p. 177). Further, in a comparative study of the 
foreign language learning attitudes and experiences of school students $(N=4312)$ in 4 European countries learning English and other FLs, Busse (2017) found that 9\% of the respondents were mostly driven 'by an appreciation of and a general interest in language learning’ (p. 576). Reflecting on the results of these studies, she suggests that for both monolingual students who are studying a FL, and multilingual students who have experiences of two or more languages, 'the image of an ideal self speaking various languages can have a powerful effect on motivation' (p. 578).

\section{Purpose}

As in other fields in SLA, L2 motivation research needs to adopt 'a more holistic, interactive, ecological approach’ in which the future-oriented identities that influence students’ motivation are conceptualized as a product of learning/using several languages (Duff, 2017, p. 604). Research by Henry (2017), Busse (2017) and Ushioda (2017) points to the existence of multilingual identities that, in conjunction with language-specific identities, have the potential to influence motivation. While proposals that people in multilingual learning contexts can develop motivationally important future-oriented multilingual identities are supported by the experiences of individual learners, construct validity for the proposed ideal multilingual self (Henry, 2017, Ushioda, 2017) has yet to be established. In a context where school students learn two or more LOTEs concurrently, and using latent variable modeling, the purpose of this study is to determine whether discriminant validity for the ideal multilingual self can be established (i.e., that it is conceptually different from the ideal L2 self), and whether it would have a unique influence on motivation. For this purpose, the following hypotheses were constructed: 
H1 That the ideal L2 self and the ideal multilingual would be conceptually distinct, and,

H2 That the ideal multilingual self would have a positive influence on intended effort in learning a LOTE

\section{Method}

\section{Participants}

The participants were 324 students ( $m=151, \mathrm{f}=172$ ) enrolled at two schools in the western part of Sweden (school A = 190, school B = 133). The students were enrolled in grade 7 ( $n=113$ ), grade 8 ( $n=112)$ and grade $9(n=98)$. With the exception of students not learning a FL and who did not participate, they represent the total populations at the two schools. As in many northern European settings, in Sweden motivation to learn LOTEs is generally low, not least when compared with English. For LOTEs, Swedish students are among the lowest achievers in Europe. In accordance with the European Union's promotion of plurilingualism, the government's aim is that a majority of students should learn a LOTE. However, of roughly $80 \%$ who begin learning (either in grade 6 or grade 7), the number still learning a LOTE falls to $60 \%$ by grade 9 . In grades 6, 7 and 8, study is at a level equivalent to the CEFR A1 level, and in grade 9 to CEFR A2 (Henry, 2012).

With this background in mind, two schools where it was anticipated that attitudes to foreign language learning and multilingualism would be more positive than in the general school population were selected for the study. School A is a city school with an international profile. Language learning is actively promoted at the school. Not only do nearly all students learn a LOTE, around one third also learn a second LOTE. The languages offered, both as first and 
second LOTEs, are French, German and Spanish. The same languages are offered at school B. Here, however, there is no special promotion of foreign languages, and students learn only one LOTE. However, the school has an international outlook. Global perspectives inform working practices, the school's vision is to educate for international citizenship, and at all levels students engage in various international exchange programs.

\section{Instrument}

The questionnaire comprised 9 items relating to the criterion measure of intended effort, and 7 items relating the ideal L2 self. These items were specifically formulated in relation to the language learnt as a first LOTE; that is, students learning French received a questionnaire containing items relating to French. These items replicate those previously used in a Swedish context with similarly-aged students by Henry and Cliffordson (2016).

Also included were 7 items relating to the ideal multilingual self variable. These items had the same stem formulations as the items measuring the ideal L2 self, but were modified to focus on multilingualism. The items used in the subsequent modelling process are presented in Table 1.

\section{Piloting and procedures}

Although the items for the criterion variable and for the ideal L2 self have previously been used in a Swedish context, the items designed to measure the ideal multilingual self have not. For this reason, piloting took place. A group of five grade 9 students completed the questionnaire. In an immediately subsequent group interview conducted by the first author, these students went through the questionnaire item-by-item, discussing formulations, and identifying any that were problematic. Afterwards, changes were made to a small number of items. 
Table 1, Descriptive statistics of items

\begin{tabular}{|c|c|c|c|c|c|}
\hline Variables & $N$ & $\begin{array}{l}\text { Missing } \\
\quad N\end{array}$ & $m$ & sd & Item wording \\
\hline \multicolumn{6}{|l|}{$\begin{array}{l}\text { Ideal } \\
\text { Multilingual } \\
\text { Self }\end{array}$} \\
\hline IDMS1 & 319 & 5 & 3.56 & 1.09 & $\begin{array}{l}\text { Communicating with people in several different } \\
\text { languages other than Swedish and the language I speak } \\
\text { with my parents is not going to be a problem for me in } \\
\text { the future }\end{array}$ \\
\hline IDMS2 & 319 & 5 & 3.41 & 1.16 & $\begin{array}{l}\text { When I think about the future I can see myself } \\
\text { speaking several different languages other than } \\
\text { Swedish and the language I speak with my parents in } \\
\text { many different situations. }\end{array}$ \\
\hline IDMS3 & 318 & 6 & 3.19 & 1.26 & $\begin{array}{l}\text { Being able to speak several different languages other } \\
\text { than Swedish and the language I speak with my parents } \\
\text { will be a part of who I am in the future. }\end{array}$ \\
\hline IDMS4 & 319 & 5 & 3.31 & 1.27 & $\begin{array}{l}\text { When I think about who I will be in the future, I see } \\
\text { myself as someone who speaks several different } \\
\text { languages other than Swedish and the language I speak } \\
\text { with my parents. }\end{array}$ \\
\hline \multicolumn{6}{|l|}{$\begin{array}{l}\text { Ideal L2 } \\
\text { Self }\end{array}$} \\
\hline IDL2_1 & 322 & 2 & 3.39 & 1.22 & $\begin{array}{l}\text { I see myself as a person who in the future is good at } \\
\text { speaking French }\end{array}$ \\
\hline IDL2_2 & 322 & 2 & 3.25 & 1.27 & $\begin{array}{l}\text { I see myself as a person who in the future will use } \\
\text { French in contact with people outside Sweden. }\end{array}$ \\
\hline IDL2_3 & 319 & 5 & 2.95 & 1.26 & $\begin{array}{l}\text { When I think about the future I can see myself } \\
\text { speaking French in many different situations }\end{array}$ \\
\hline IDL2_4 & 321 & 3 & 2.69 & 1.27 & $\begin{array}{l}\text { Being able to speak French will be a part of who I am } \\
\text { in the future. }\end{array}$ \\
\hline \multicolumn{6}{|l|}{$\begin{array}{l}\text { Intended } \\
\text { Effort }\end{array}$} \\
\hline EFF1 & 320 & 4 & 3.73 & 0.97 & I work hard learning French \\
\hline EFF2 & 319 & 5 & 3.64 & 1.10 & I am prepared to work hard to learn French \\
\hline EFF3 & 322 & 2 & 3.06 & 1.13 & I put a lot of time and energy into studying French \\
\hline EFF4 & 320 & 4 & 3.11 & 1.11 & I focus a lot on studying French \\
\hline
\end{tabular}


Note 1. Here, French is used as an example. Note 2. In the instructions given to students, the formulation 'other than Swedish and the language I speak with my parents' was explained to relate to situations where the L1 of one of both parents was not Swedish.

The questionnaire, which was completed anonymously, was administered to study participants personally by the authors in December 2015 in accordance with the ethical guidelines of the Swedish Research Council. In school B, where classes were larger, support was received from research assistants. Administrations took place in the students' ordinary classrooms during morning lessons, and class teachers were always present.

\section{Analyses}

In order to test the two hypotheses, data was analyzed using structural equation modelling (SEM). The SEM was conducted using Mplus 6.1 (Muthén \& Muthen, 1998-2010) under the STREAMS (Gustafsson \& Stahl, 2005) environment.

\section{Missing data}

Even though there is only a small amount of missing information in the data (less than $2 \%$ across all items, see Table 1), the missing data modeling procedure implemented in the Mplus program was used (Muthén, Kaplan \& Hollis, 1987). Data is assumed to be missing at random (MAR), which implies that missingness is allowed to depend on observed values but not on missing values (Shaefer \& Graham, 2002).

\section{Goodness of fit}

The $\chi^{2}$ goodness-of-fit test, the root mean square error of approximation (RMSEA), the comparative fit index (CFI), and the standardized root mean square residual (SRMR) were all used as measures of model fit. When the $\chi^{2}$ goodness-of-fit test did not produce significant results, additional goodness-of-fit measures were not necessary. However, when the $\chi 2$ goodness-of-fit test indicated a significant result, the RMSEA, CFI and SRMR were used. The 
RMSEA is an established tool for evaluating model fit since it takes account of both the number of observations and the number of free parameters (Brown, 2015). Values below 0.05 generally indicate a close fit, and values between 0.05 and 0.08 indicate an acceptable model fit (Browne \& Cudeck, 1993). The values of CFI can range from 0 to 1 , where values equal to or larger than 0.95 indicate a good model fit. The CFI is based on a comparison of the $\chi^{2}$ value of the model and the $\chi^{2}$ of the null model. SRMR is an absolute fit index and can range from 0 to 1 , where 0 is indicative of perfect model fit and values .08 or smaller indicate an acceptable model fit (Brown, 2015).

\section{Results}

\section{H1 That the ideal L2 self and the ideal multilingual would be conceptually distinct}

First, measurement models for the ideal L2 self (IdealL2) (Model A), and ideal multilingual selves (IdealMS) (Model B) were set up in order to test model fit. Items yielding low factor loadings, and items where there were cross-loadings between the two constructs were removed. Modification indices identified covariances between two items in each construct. These covariances likely represent shared variance due to the shared methodology. The goodness of fit indices for both measurement models yielded non-significant $\chi 2$ values (Table 2). The factor loadings were high. For the ideal L2 self they were between .75 and .86, and for the ideal multilingual self the factor loadings were between .80 and .95 (Figures 1 and 2). The latent variable IdealL2 accounted for between $56 \%$ and $74 \%$ of the variance in each indicator, while the latent variable IdealMS accounted for between $64 \%$ and $90 \%$ of the variance in each indicator. High factor loadings and low cross-loadings are indicators that the latent constructs have low overlap. This means that discriminant validity for the ideal multilingual self can be established. As an additional measure, the correlation between the two constructs was 
investigated. This was found to be .64, a magnitude well below the recommended .70 needed to establish discriminant validity (Brown, 2015). Finally, it can be noted that the Cronbach's alphas for the Ideal L2 self, Ideal multilingual self and Intended Effort scales were .90, .92 and .90 respectively, thus indicating that the scales have internal consistency.

Table 2, Model fit indices for models A-C

\begin{tabular}{l|rrccrr}
\hline Model & $X^{2}$ & $d f$ & $p$-value & CFI & RMSEA & SRMR \\
\hline A & 0.434 & 1 & 0.51 & & & \\
B & 0.009 & 1 & 0.92 & & & \\
C & 135.633 & 48 & 0.00 & 0.970 & 0.075 & 0.04 \\
\hline
\end{tabular}

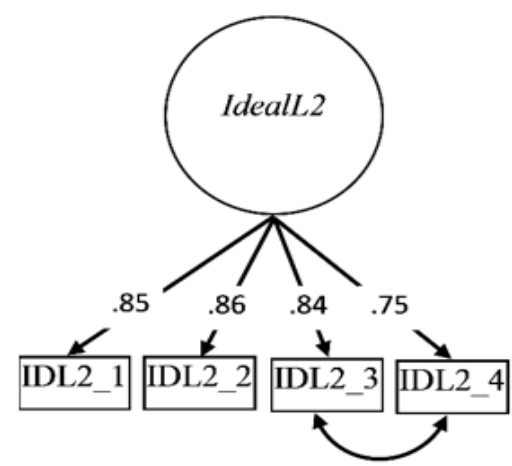

Figure 1, Model A: Measurement model ideal L2 self 


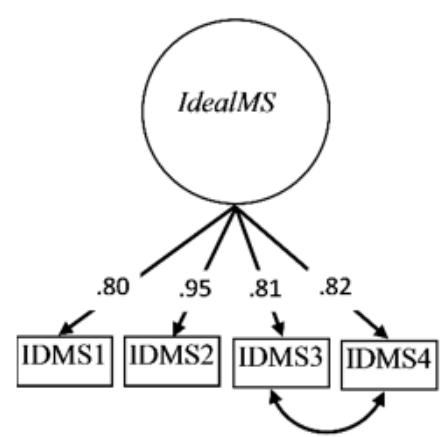

Figure 2, Model B: Measurement model for ideal multilingual self

\section{H2 That the ideal multilingual self would have a positive influence on intended effort in}

\section{learning a LOTE}

To test whether the ideal multilingual self would have a positive influence on intended effort to learn the target LOTE, a path-model was set up. First IdealMS was related to Effort. Then, in a second step, Ideal L2 was added as mediating variable (Model C, Figure 3). The model fit indices were below cut-off values (Table 2). All factor loadings were significant, and the relations between IdealMS and IdealL2 (.64), and between IdealL2 and Effort (.65) were both significant. However, the direct relation between IdealMS and Effort was low and nonsignificant. This indicates that the ideal multilingual self influences intended effort indirectly $(.42)^{\mathrm{iv}}$ through the ideal L2 self.

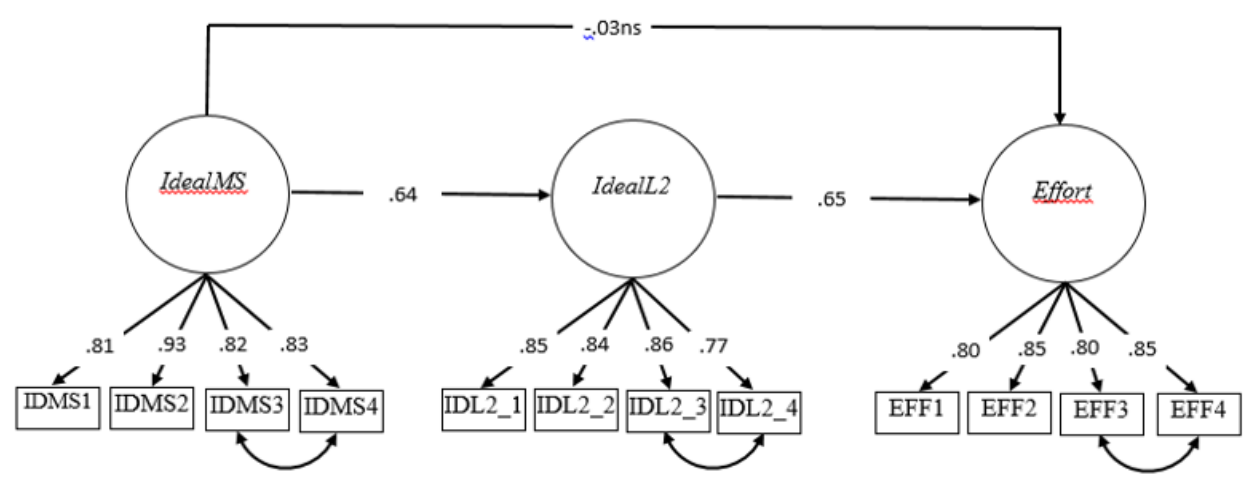

Figure 3, Model C: Path model with direct and indirect relations between constructs 


\section{Discussion}

\section{Establishing construct validity for the ideal multilingual self}

Campbell and Fiske (1959) argue that construct validity can be established using convergent and discriminant techniques. The results offer support for the discriminant validity of the ideal multilingual self, the degree of overlap between it and the ideal L2 self indicating that the two constructs should be understood as conceptually distinct. This finding is important since it suggests that as a potential source of motivation, the desire to achieve multilingual competence is separate to the desire to achieve competence in a specific language. Having established discriminant validity for the construct, the second stage of the factor analytic modelling involved measuring the effect of the ideal multilingual self on the criterion variable. Results showed that it did not have a direct effect on motivation to learn the chosen LOTE. However, it did have an indirect effect, mediated via the ideal L2 self.

\section{An indirect effect}

The first thing to note is that the variance explained on the criterion variable by the ideal L2 self (42\%) is substantial. Indeed, it is in the range normally found where English is the TL and aspiration to achieve communicative skills can be understood as part of the development of a bicultural identity where English represents and mediates the person's relationship to a global culture (Dörnyei \& Ryan, 2015). That the explained variance is of such magnitude is almost certainly a consequence of the sampling strategy, and should not be regarded as indicative of a more general phenomenon. Indeed, for students in northern Europe learning LOTEs, a much weaker relation with the criterion variable would normally be expected.

The lack of a direct effect on intended effort, but a substantial indirect effect, can be understood in a number of ways. First, the ideal multilingual self is conceptualized as an 
emergent property of cross-linguistic influences, that is to say an outcome of positive interactions between the ideal Lx self and the ideal Ly self (Henry, 2017). As such, it has a higher-level function. It is this antecedent effect that is seen in the current model. Importantly, while the predictor variable (ideal L2 self) and the criterion variable (intended effort) both relate to the particular LOTE that the student is learning (French/German/Spanish), the ideal multilingual self taps into a broader and more diffuse dimension of an nascent identity. This can explain why the effect is only indirect.

The second point to note is that because the ideal multilingual self is not related to a specific language, but instead involves a more holistic future-oriented self-conception, it is likely to be construed at a higher level of abstraction (Henry, 2017). As a psychologically distant state (Liberman \& Trope, 1998), the vison of being a speaker of multiple languages is less likely to be mentally connected to particular situations or events than is the case for the ideal L2 self. Moreover, as a higher-level self-construal, the ideal multilingual self may not easily lend itself to mental concretization. Even though high-level construals can be potentially powerful (Fujita, Trope, \& Liberman, 2015), the ideal multilingual self is likely to be generally less accessible and less frequently triggered than the ideal L2 self, thus providing an additional explanation as to why the effect is indirect.

Finally, it needs to be recognized that the mental nexus between imagining speaking a particular foreign language and expending effort learning the language in school is likely to be more robust than connections between desiring to be/become multilingual and effort directed to learning the language in question. In the current study, this more abstract nexus is likely to be compounded by the relatively low age of the participants (13-15), and by the modest levels of proficiency aimed at (CEFR A1/A2). For these and other younger teenagers, growing maturity 
and increased intercultural experiences can have the effect that abstract values attaching to multilingualism and a nascent multilingual self-concept can become more tangible over time. Specifically, it is plausible to assume that with age, increased competency, and a greater number of interactions with speakers of other languages, the desire to be/become multilingual may become more directly associated with learning a particular foreign language.

\section{A context of meaning}

In the light of the current findings, the ideal multilingual self can perhaps best be understood as creating a 'context of meaning' within which the ideal L2 self is nurtured. This 'context of meaning' can have two specific functions. First, it provides an additional layer of purpose to the desire to gain proficiency in a LOTE. That is, developing language skills assumes a value and significance beyond the development of a desired identity as an emerging speaker of the TL. Specifically, becoming a TL-speaker is valued, and effort in learning is expended because skillsdevelopment becomes part of a more general process of wanting to be/become multilingual.

The second function of the 'context of meaning' is to protect the ideal L2 self from the negative influences of other competing L2 selves (see Henry, 2010, 2011), and from societal discourses questioning the value of learning LOTEs (Ushioda, 2017). When threats to a possible self are systematic, processes of downward revision occur (Carroll, Shepperd, \& Arkin, 2009). This means that, over time, an ideal L2 self can lose its strength, the consequence being that the discomfort-generating discrepancy will likely diminish (Henry, 2015). For LOTEs, a particular threat to an ideal L2 self comes from English. As Dörnyei and Al-Hoorie (2017) have suggested, 'arguably the most important unique characteristic of the motivation to learn LOTEs is the fact that the process typically takes place in the shadow of Global English' (p. 457). However, when an ideal multilingual self is also developed, the goal of being/becoming multilingual can function 
in a way that offsets threats, and reduces the likelihood of downward self-revisions. Reflecting on the current results, one possible interpretation for the substantial proportion of explained variance accounted for by the ideal L2 self is that the ideal multilingual self creates a protective 'context of meaning'.

\section{The Ideal Multilingual Self and Holistic Approaches to Multilingual Education}

Changes in the nature of communication across and within languages brought about by globalization mean that language education needs to be reconceptualized in ways that take account of the diversity of reasons for learning (Duff, 2017; Leung \& Scarino, 2016). Arguing that learning objectives are often too narrowly-defined, and generally mesh poorly with the needs and interests of individual learners, Leung and Scarino (2016) argue for a 'holistic and expansive consideration' of the goals of language learning (p. 82). As Duff (2017) suggests, 'more fluid, less criterion-referenced notions of competence' can motivate learners 'to take part in language study or other activities in support of language development without fear of falling far short of target-language norms’ (p. 602). To achieve a better fit with people’s varying purposes and desires, goals for foreign language learning need therefore to emphasize the development of multilingual capabilities, and the expansion of meaning-making repertoires.

Motivational strategies and interventions created around visions of becoming a competent speaker of a particular TL resonate poorly with multilingually-oriented goals. Because of its monolingual framing, the ideal L2 self can function to instill separationist, compartmentalized views of linguistic accomplishment. In the same way that languages constitute elements of a common repertoire, language-speaking identities also need also to be conceptualized as constituents of larger multilingual systems. If, as currently, strategies and interventions in the Lx classroom are focused exclusively on generating and nurturing the 'ideal Lx self', with similar 
initiatives in the Ly classroom directed to the 'ideal Ly self', the self-guides risk developing as 'two solitudes' - to borrow Cummins' well-known term (2005, p. 588) - rather than integrated dimensions of a holistic multilingual identity.

Grounded in a similar non-separationist logic as conceptions of linguistic multicompetence (Cook, 2016), translanguaging (Garcia \& Li Wei, 2014), and translingual practice (Canagarajah, 2013), the conceptualization of the ideal multilingual self as a composite and multidimensional self-conception that transcends but also supports the ideal Lx self and the ideal Ly self, can play an important role in a multilingual education. In an expanded multilingual agenda for language learning/language teaching with reconceptualized learning goals, motivational strategies aimed at developing an integrated ideal multilingual self can become a part of curricula initiatives that position individual languages as elements within broader repertoires, that frame skills as distributed across languages, and which encourage resourcefulness, innovation and multilingual accomplishments.

However, as Cenoz and Gorter (2011a, 2011b) make clear, a holistic approach embodied in policy alone is not sufficient. Local implementation is required where language teachers create strategies that enable students to explore the commonalities shared between languages, and develop language awareness and linguistic multicompetence. As they explain, teaching with a multilingual focus means taking account of all the languages the leaner has experience of. Specifically, it involves the creation of activities designed to enhance metalinguistic awareness, and the construction of an integrated framework that systematically highlights 'connections between the languages being learned at school' (Cenoz \& Gorter, 2011b, p. 360).

However, while teachers of FLs may understand the importance of multilingualism and value the ambitions espoused in multilingual pedagogies, the systematic use of translanguaging 
practices in classrooms places high demands on pedagogical and linguistic skills. As Garcia and Li Wei $(2014,2015)$ make clear, the success of translanguaing is not only a question of language allocation policies and the ways in which in local settings language teaching is organized and assigned. Equally, the success of efforts to create spaces where the full of language resources can be exploited involves a sensitivity on the part of the teacher to translanguaging affordances in classroom interaction. While the moment-by-moment, strategic use of the student's language resources might be ‘the art of translanguaging as pedagogy’ (Garcia \& Li Wei, 2015, p. 233), developing teachers' linguistic awareness to a degree than can successfully scaffold such practices is a challenging undertaking. In comparison with the time-consuming development of teachers’ multilingual awareness, strategies aimed at developing students’ ideal multilingual selves can be easier for teachers to embrace and implement. Moreover, for teachers who perceive a lack of opportunity for concrete forms of collegial collaboration (Haukås, 2016), strategy packages aimed at developing students' ideal multilingual selves could provide an important platform upon which school-wide, cross-language initiatives could be constructed.

\section{Conclusion and Future Research}

While the current findings are not intended to be generalizable beyond the very particular context in which the research was conducted, they provide initial support for the construct validity of the ideal multilingual self. Specifically, they show that the ideal L2 self and the ideal multilingual self are distinct constructs. However, discriminant validity is one indicator of construct validity (Campbell \& Fiske, 1959). Therefore, future research directed to establishing convergent validity - for example using hierarchical modelling to examine correlations between the ideal multilingual self variable and the common variance attributable to the ideal L2 selves of different TLs - would be of value. 
In offering support for the validity of the ideal multilingual self, the current study provides justification for programs of research designed to more fully explore the motivational potential of the construct, and its relationship with the ideal L2 self. In particular, research would be usefully directed to exploring the ways in which the ideal multilingual self might generate additional meaning in multiple language learning and, in longitudinal, complexity-informed studies, to examining the circumstances surrounding its emergence and evolution. In this respect, research investigating the trajectories of learners' ideal multilingual selves in relation to the trajectories of the ideal L2 selves of the different TLs would be of significant value. For older students and adults, it is arguable that the ideal multilingual self may have a direct effect on intended effort as a consequence of how, over time, a nascent multilingual identity can achieve greater integration within the person's core self-conceptions.

The other area where research efforts should be directed involves the development and evaluation of pedagogical interventions designed to support students in developing an ideal multilingual self. Returning to the specific setting in which the study was carried out, despite international profiles at both schools, language teaching was not coordinated. Nor had schoolwide pedagogies or cross-language teaching initiatives been developed. Thus, while students might harbor a desire to be/become multilingual, even in situations where the TL is salient the ideal multilingual self may not be easily accessible or frequently activated. However, in circumstances where things happen in language classrooms that lead to a more regular activation of the ideal multilingual self - for example when teachers draw attention to crosslinguistic influences or include multilingual-self strategies as a recurring part of teaching - the ideal multilingual self may also have a direct effect on motivation. For this reason interventionoriented research would be extremely valuable. 
Finally, it needs to be noted that the motivational strategies described in practitioner-oriented literature have an exclusive focus on enhancing motivation to learn single TLs. Unfortunately, the monolingual framing of these strategies resonates poorly with efforts to develop translanguaging and translingual practices. Indeed, because motivational strategies focus on the separate development of the student's ideal Lx and Ly selves, through an implicit reassertion of separationist and monolingual norms, they can undermine attempts at developing linguistic multicompetence. For this reason, the ideal multilingual self needs to be highlighted in the literature on motivational strategies made available to teachers (e.g. Dörnyei, 2001; Hadfield \& Dörnyei, 2013) so that it can make a contribution to multilingual pedagogies emphasizing the connectedness of languages and integration of language teaching (Cenoz \& Gorter, 2011a, 2011b).

\section{Acknowledgements}

We would like to thank the students and teachers at the two schools, and our colleagues who assisted in the data collection. We would also like to thank the anonymous reviewers of this paper.

\section{References}

Aronin, L. (2016). Multi-competence and dominant language constellation. In V. Cook \& Li Wei (Eds.), The Cambridge Handbook of Linguistic Multicompetence (pp. 142-163). Cambridge: Cambridge University Press.

Block, D. (2015). Becoming multilingual and being multilingual. In J. Cenoz \& D. Gorter (Eds.). Between language learning and translanguaging (pp. 225-237). Cambridge: Cambridge University Press. 
Boo, Z., Dörnyei, Z., \& Ryan, S. (2015). L2 motivation research 2005-2014: Understanding a publication surge and a changing landscape. System, 55, 145-157.

Brown, T. A. (2015). Confirmatory factor analysis for applied research. London: The Guilford Press.

Browne, M. W., \& Cudeck, R. (1993). Alternative ways of assessing model fit. In Bollen, K. A., \& Long, J. S (Eds.), Testing structural equation models (pp. 136-162). Newbury Park, CA: Sage.

Busse, V. (2013). An exploration of motivation and self-beliefs of first year students of German. System, 41, 379-398.

Busse, V. (2015). Überlegungen zur Förderung der deutschen Sprache an englischen Universitäten aus motivationspsychologischer Perspektive [Reflections on promoting the German language at English universities from the perspective of motivational psychology]. Deutsch als Fremdsprache, 52, 172-182.

Busse, V. (2017). Plurilingualism in Europe: Exploring attitudes towards English and other European languages among adolescents in Bulgaria, Germany, the Netherlands and Spain. Modern Language Journal, 101, 3, 566-582.

Campbell, D. T. \& Fiske, D. W. (1959). Convergent and discriminant validation by the multitraitmultimethod matrix. Psychological Bulletin, 56, 81-105.

Canagarajah, A. S. (2013). (Ed.). Literacy as translingual practice: Between communities and classrooms. New York: Routledge.

Carroll, P.J., Shepperd, J. A. and Arkin, R. M. (2009) Downward self-revision: Erasing possible selves. Social Cognition 27, 550-578. 
Cenoz, J., \& Gorter, D. (2011a). A holistic approach to multilingual education: Introduction. The Modern Language Journal, 95, 339-343.

Cenoz, J., \& Gorter, D. (2011b). Focus on multilingualism: a study of trilingual writing. The Modern Language Journal, 95, 356-369.

Cenoz, J., \& Gorter, D. (2015). Towards a holistic approach in the study of multilingual education. In J. Cenoz \& D. Gorter (Eds.), Multilingual education: Between language learning and translanguaging (pp. 1-15). Cambridge: Cambridge University Press.

Cook, V. (2016). Premises of multi-competence. In V. Cook \& Li Wei (Eds.), The Cambridge handbook of linguistic multicompetence (pp. 1-25). Cambridge: Cambridge University Press.

Cummis, J. (2005). A proposal for action: strategies for recognizing heritage language competence as a learning resource within the mainstream classroom. The Modern Language Journal, 89, 585-592.

De Angelis, G. (2007). Third or additional language acquisition. Clevedon: Multilingual Matters.

Dewaele, J. M. (2011). Reflections on the emotional and psychological aspects of foreign language learning and use. Anglistik: International Journal of English Studies 22, 1, 2342.

Dörnyei, Z. (2001). Motivational strategies in the language classroom. Cambridge: Cambridge University Press.

Dörnyei, Z. (2005). The psychology of the language learner: Individual differences in second language acquisition. London: Lawrence Erlbaum.

Dörnyei, Z. (2009). The L2 Motivational Self System. In Z. Dörnyei \& E. Ushioda (Eds.), Motivation, language identity and the L2 self (pp. 9-42). Bristol, UK: Multilingual Matters. 
Dörnyei, Z., \& Al-Hoorie, A. (2017). The motivational foundation of learning languages other than Global English: Theoretical issues and research directions. Modern Language Journal, 101, 455-468.

Dörnyei. Z., \& Ryan, S. (2015). The psychology of the language learner revisited. New York: Routledge/Taylor \& Francis.

Dörnyei, Z., \& Ushioda, E. (2011). Teaching and researching motivation. Harlow: Longman.

Douglas Fir Group. (2016). A transdisciplinary framework for SLA in a multilingual world. Modern Language Journal, 100 (Supplement 2016), 19-47.

Duff, P. (2017). Commentary: Motivation for learning languages other than English in an Englishdominant world. Modern Language Journal, 101, 3, 597-607.

Fujita, K., Trope, Y., \& Liberman, N. (2015). On the psychology of near and far: A construal level theoretical approach. In G. Keren \& G. Wu (Eds.), The Wiley Blackwell handbook of judgment and decision making volume 1 (pp. 404-429). Chichester, UK: Wiley Blackwell.

Garcia, O., \& Li Wei. (2014). Translanguaging: language, bilingualism, education. Basingstoke, UK: Palgrave Macmillan.

Garcia, O., \& Li Wei (2015). Translanguaging, bilingualism, and bilingual education. In W. E. Wright, S. Boun, \& O. Garcia (Eds.), The handbook of bilingual and multilingual education (pp. 223-240). Chichester: John Wiley.

Gardner, R. C. (1985). Social psychology and second language learning: The role of attitudes and motivation. London: Edward Arnold.

Gustafsson, J.-E., \& Stahl, P.-A. (2005). STREAMS 3.0 user's guide. Mölndal, Sweden: Multivariateware. 
Hadfield, J., \& Dörnyei, Z. (2013). Motivating learning. Harlow: Longman.

Haukås, Å (2016). Teachers’ beliefs about multilingualism and a multilingual pedagogical approach. International Journal of Multilingualism, 13, 1-18.

Henry, A. (2010). Contexts of possibility in simultaneous language learning: using the L2 Motivational Self System to assess the impact of global English. Journal of Multicultural and Multilingual Development, 31, 2, 149-162.

Henry, A. (2011). Examining the impact of L2 English on L3 selves: A case study. International Journal of Multilingualism 8(3) 235-255.

Henry, A. (2012). L3 Motivation. Gothenburg: Gothenburg University Press.

Henry, A. (2014). The motivational effects of crosslinguistic awareness: Developing third language pedagogies to address the negative impact of the L2 on the L3 self-concept. Innovation in Language Teaching and Learning 8(1) 1-19.

Henry. A. (2015). The Dynamics of Possible Selves. In Z. Dörnyei, P.D. MacIntyre \& Henry, A. (Eds.). Motivational Dynamics in Language Learning (pp. 83-94). Bristol, England: Multilingual Matters.

Henry, A. (2016). Enablements and constraints: inventorying affordances associated with lingua franca English. International Journal of Bilingual Education and Bilingualism, 19, 5, 488510.

Henry, A. (2017). L2 motivation and multilingual identities. Modern Language Journal, 101, 3, 548-565.

Henry, A. \& Cliffordson, C. (2016). The impact of out-of-school factors on motivation to learn English: Self-discrepancies, beliefs, and experiences of self-authenticity. Applied Linguistics. 
Higgins, E.T. (1987). Self-discrepancy: A theory relating self and affect. Psychological Review, 94, 319-340.

Jessner, U. (2006). Linguistic awareness in multilinguals: English as a third language. Edinburgh, UK: Edinburgh University Press.

Kramsch, C., \& Huffmaster, M. (2015). Multilingual practices in foreign language study. In J. Cenoz \& D. Gorter (Eds.), Multilingual education: Between language learning and translanguaging (pp. 114-136). Cambridge: Cambridge University Press.

Lasagabaster, D. (2017). Language learning motivation and language attitudes in multilingual Spain from an international perspective. Modern Language Journal, 101, 3, 583-596.

Liberman, N., \& Trope, Y. (1998). The role of feasibility and desirability considerations in near and distant future decisions. A test of temporal construal theory. Journal of Personality and Social Psychology, 75, 5-18.

Leung, C., \& Scarino, A. (2016). Reconceptualizing the nature of goals and outcomes in language/s education. Modern Language Journal, 100 (Supplement 2016), 81-95.

May, S. (2014). Introducing the "multilingual turn”. In S. May (Ed.), The multilingual turn: Implications for SLA, TESOL and bilingual education (pp. 1-6). New York: Routledge/Taylor \& Francis.

Muthén, L.K., \& Muthén, B.O. (1998-2010). Mplus User’s Guide (6th ed.). Los Angeles: Muthén \& Muthén.

Muthén, B., Kaplan, D., \& Hollis, M. (1987). On structural equation modelling with data that are not missing completely at random. Psychometrica, 52(3), 431-462.

Oakes, L. (2013). Foreign language learning in a 'monoglot culture': Motivational variables amongst students of French and Spanish at an English university. System, 41, 178-191. 
Ortega, L. (2014). Ways forward for a bi/multilingual turn in SLA. In S. May (Ed.), The multilingual turn: Implications for SLA, TESOL and bilingual education (pp. 32-53). New York: Routledge/Taylor \& Francis.

Pavlenko, A. (2006). Bilingual selves. In A. Pavlenko (Ed), Bilingual minds: Emotional experience, expression and representation (pp. 1-33). Clevedon, UK: Multilingual Matters.

Schafer, J. L., \& Graham, J. W. (2002). Missing data: Our view of the state of the art. Psychological Methods, 7(2), 147-177.

Ushioda, E. (2017). The impact of global English on motivation to learn other languages: Towards an ideal multilingual self. Modern Language Journal, 101, 3, 469-482.

Ushioda, E. \& Dörnyei, Z. (2017). Beyond Global English: Motivation to Learn Languages in a Multicultural World: Introduction to the Special Issue. Modern Language Journal, 101, 3, 451-454.

'Following the arguments of Cenoz and Gorter (2015), and Block (2015), in this article the terms 'being' and 'becoming' multilingual are understood as 'distinguishable yet interrelated and interlinked phenomena’ (Block, 2015, p.236)

${ }^{\text {ii }}$ In self-discrepancy theory (Higgins, 1987), future self-guides represent points of comparison that are reconciled through the individual's behaviors. In the L2 Motivational Self System the two self-guides are the Ideal L2 Self and the Ought-to L2 Self (Dörnyei, 2009).

iii It should be noted that there were also participants in Pavlenko’s (2006) study whose experiences of bi/multilingualism were not positive. For people for whom learning an additional language involved a sense of loss, transitioning between languages constituted a source of 
discomfort, and identity experiences connected with being multilingual involved feelings of fragmentation, incompleteness, and inadequacy.

iv Calculated by multiplying the coefficients for the direct effects, following the paths in Figure 3. 